\title{
Perforación vesical espontánea tras cistoplastia en la infancia
}

\author{
M.L. Martínez del Castillo*, C. Miguélez Lago**, M. García Mérida**, E. Galiano Duro**, \\ N. García Soldevila*, E. Valls Moreno*** \\ *Cirugía Pediátrica. **Urología Pediátrica. ***Servicio de Radiodiagnóstico. Hospital Materno-Infantil, del \\ Hospital Regional Universitario Carlos Haya. Málaga.
}

Actas Urol Esp 2005; 29 (9): 869-878

\section{RESUMEN}

PERFORACIÓN VESICAL ESPONTÁNEA TRAS CISTOPLASTIA EN LA INFANCIA

Objetivos: La perforación espontánea de una cistoplastia es un problema grave y potencialmente fatal, si no se diagnostica y se trata a tiempo. Se pretende: 1) buscar una prevención analizando los factores de riesgo, 2) identificar los principales datos de sospecha diagnóstica y 3) valorar el resultado de los tratamientos realizados.

Material y Método: De 30 pacientes pediátricos con cistoplastia, 5 presentaron 8 perforaciones (16,6\%). Se revisan los diversos factores influyentes, la clínica, los tratamientos y la evolución.

Resultados: El tiempo medio transcurrido entre la cistoplastia y la perforación fue 8,2 años. Los principales factores de riesgo han sido una resistencia uretral que permitía continencia, y una insuficiente realización temporal del sondaje intermitente (SI). En los 8 episodios hubo dolor y distensión abdominal. La ecografía mostró líquido libre intraperitoneal en 5, múltiples quistes peritoneales en 1, e imagen sugestiva de plastrón apendicular en otro. La cistografía sólo mostró paso de contraste a la cavidad peritoneal en 3. El tratamiento inicial fue conservador, sin cirugía, en los 7 episodios diagnosticados preoperatoriamente, siendo la evolución favorable en 3 $(42,8 \%)$; los otros 4 necesitaron tratamiento quirúrgico, con buena evolución en todos. De los 5 pacientes, 2 (40\%) presentaron 3 recidivas en un tiempo medio de 5 años. La supervivencia es del $100 \%$.

Conclusiones: El 16,6\% de los pacientes con cistoplastia de esta serie, ha tenido uno o más episodios de perforación vesical espontánea. Los factores de riesgo más significativos son una resistencia uretral alta y la inadecuada realización del SI. Los pacientes con cistoplastia y sus familias deben conocer esta complicación, sus factores de riesgo y sus sintomas, para prevenirla o facilitar un diagnóstico precoz.

Palabras clave: Vejiga neuropática. Niños. Cistoplastia. Perforación vesical.

\section{ABSTRACT}

SPONTANEOUS URINARY BLADDER PERFORATION AFTER PEDIATRIC CYSTOPLASTY

Objective: The spontaneous cystoplasty perforation is a serious and potentially fatal problem if a delay in diagnosis and treatment occurs. We pretend: 1) to look for prevention analyzing the risk factors, 2) to identify the main data of diagnostic suspicion and 3) to evaluate the result of the treatments done.

Material and Methods: Out of 30 children with cystoplasty 5 of them have presented 8 perforations (16,6\%). Several influential factors, the symptoms, the treatments and the evolution are reviewed.

Results: The average time between cystoplasty and the perforation was 8,2 years. A urethral resistance that allows continence, and an insufficient intermittent catheterization, have been the main risk factors. In the 8 episodes there were abdominal pain and distension. The ultrasonography showed intraperitoneal extravasation in 5 episodes, multiple peritoneal cysts in one, and suggestive image of appendicular plastron in another one. The cystography showed intraperitoneal extravasation only in 3 cases. The initial management was conservative in the 7 episodes diagnosed before surgery, and 3 had a good evolution $(42,8 \%)$; the other 4 needed surgery with good evolution in all cases. Two of 5 patients (40\%) presented 3 relapses in an average time of 5 years. The survival is $100 \%$.

Conclusions: $16,6 \%$ of patients with cystoplasty of this series had one or more episodes of spontaneous bladder perforation. The more significant risk factors are a high urethral resistance and an inadequate intermittent catheterization. The patients with cystoplasty, and their families, must know this complication, their risk factors and symptoms to prevent it, or to facilitate an early diagnosis.

Keywords: Neurophatic bladder. Children. Cystoplasty. Urinary bladder perforation.

Trabajo realizado con la ayuda de una beca de la Fundación para la Investigación en Urología. 
$\mathrm{L}$ a cistoplastia de aumento es un tratamiento quirúrgico frecuente en pacientes con vejigas de baja capacidad, baja acomodación y presiones elevadas, para evitar el deterioro del tracto urinario superior, y mejorar la continencia. Sin embargo, aunque los resultados obtenidos suelen ser satisfactorios, no está exenta de complicaciones, tanto médicas como quirúrgicas. Una de las posibles complicaciones que puede presentar es la perforación espontánea, que es un problema relativamente frecuente, grave y potencialmente fatal. Por ello es fundamental hacer un diagnóstico y un tratamiento precoces

\section{MATERIAL Y MÉTODOS}

Entre marzo de 1990 y enero de 2005, se han intervenido en la Unidad de Urología Pediátrica del Hospital Materno-Infantil de Málaga, para la realización de una enterocistoplastia, a 30 pacientes, 18 niñas y 12 niños, cuya edad media en el momento de la cirugía fue de 7 años (rango de 2 a 13 años).

Durante este período se han producido 8 episodios de perforación espontánea de la cistoplastia en 5 de los 30 pacientes ( 3 perforaciones en un paciente, 2 en otro y 1 en el resto).

Se realiza un estudio retrospectivo de estos 5 pacientes, analizando diversas variables en relación con la patología urológica de base, la cistoplastia, los teóricos factores de riesgo, y el funcionalismo del tracto urinario inferior tras la cistoplastia (Tablas 1, 2 y 3). El sexo fue masculino en 4 y femenino en 1. La patología de base fue vejiga neuropática por mielodisplasia en 4 , y vejiga de válvulas uretrales en 1 .

Se intenta descubrir en esta serie, cuáles han sido los factores predisponentes de la perfora- ción, y los datos más significativos, tanto para el diagnóstico como para la elección del tratamiento más adecuado.

\section{RESULTADOS}

El tiempo medio de seguimiento de los 30 pacientes intervenidos de cistoplastia, desde el momento de realización de la cirugía, ha sido de 8,5 años (rango de 4 meses a 15 años).

Incidencia: 5 pacientes han presentado perforación de la cistoplastia, lo que se traduce en una incidencia de perforación del 16,6\%. El número total de perforaciones en estos 5 pacientes ha sido 8, con una media de perforaciones por paciente de 1,6.

Tipo de cistoplastia: Todas fueron cistoplastias intestinales destubulizadas; 3 con íleon y 2 con colon sigmoide.

Se analizan diversas variables en relación con la perforación, su diagnóstico y tratamiento, y la evolución posterior (Tablas 4, 5 y 6).

El tiempo medio transcurrido desde la realización de la cistoplastia hasta la presentación de la perforación ha sido de 8,2 años (rango de 2 a 14,5 años).

La edad media a la que ocurrió la perforación (primer episodio) fue 14,4 años (rango de 6 a 27 años).

El control urológico de estos 5 pacientes, en el momento de producirse las perforaciones, lo realizaba Urología Pediátrica en 2, por ser menores de 14 años, y el Servicio de Urología de Adultos en los otros 3 .

La forma de presentación clínica fue similar en todos los episodios de perforación. Hubo dolor y distensión abdominal en todos ellos (100\%), fiebre en 6 episodios (75\%), náuseas y/o vómitos en

Tabla 1

Cistoplastia

\begin{tabular}{lccccc}
\hline Caso & $\mathbf{1}$ & $\mathbf{2}$ & $\mathbf{3}$ & $\mathbf{4}$ & $\mathbf{5}$ \\
\hline Indicación & Continencia & Tracto Superior & Continencia y & Continencia y & Continencia y \\
& & & Tracto Superior & Tracto Superior & Tracto Superior \\
Edad & 10 Años & 2 Años & 8 Años & 13 Años & 8 Años \\
Tipo & Ileal & Ileal & Sigmoidea & Ileal & Sigmoidea \\
Cirugía simultánea & Manguito de Esfinter & No & Antirreflujo & No & No \\
& & & Desderivación & & \\
& & & Esfinter & & \\
\hline
\end{tabular}


Tabla 2

Factores de riesgo tras la cistoplastia

\begin{tabular}{|c|c|c|c|c|c|}
\hline Caso & 1 & 2 & 3 & 4 & 5 \\
\hline Catéter VP & No & Sí & Sì & Sí & No \\
\hline Infecciones & No & Asintomáticas & No & No & No \\
\hline Litiasis & No & No & No & No & No \\
\hline Moco & Sí & Sí & Sí & Sì & Sí \\
\hline $\mathrm{Si}$ & 4/día & 4-5/día & 4/día & 4/día & 4/día \\
\hline
\end{tabular}

Abreviaturas: Catéter VP: Catéter Ventrículo-peritoneal. SI: Sondaje Intermitente.

Tabla 3

Funcionalismo del tracto urinario inferior tras la cistoplastia

\begin{tabular}{|c|c|c|c|c|c|}
\hline Caso & 1 & 2 & 3 & 4 & 5 \\
\hline Sensibilidad & Sí & Sí & Sí & Sí & Sí \\
\hline Continencia & Total & Diurna $>3 h$ & Total & Total & Total \\
\hline CVM & $373 \mathrm{ml}$ & $458 \mathrm{ml}$ & $325 \mathrm{ml}$ & $448 \mathrm{ml}$ & $540 \mathrm{ml}$ \\
\hline PV a CVM & $14 \mathrm{~cm} \mathrm{H}_{2} \mathrm{O}$ & $11 \mathrm{~cm} \mathrm{H}_{2} \mathrm{O}$ & $20 \mathrm{~cm} \mathrm{H}_{2} \mathrm{O}$ & $8 \mathrm{~cm} \mathrm{H}_{2} \mathrm{O}$ & $16 \mathrm{~cm} \mathrm{H}_{2} \mathrm{O}$ \\
\hline Acomodación & $26 \mathrm{ml} / \mathrm{cm} \mathrm{H}_{2} \mathrm{O}$ & $41 \mathrm{ml} / \mathrm{cm} \mathrm{H}_{2} \mathrm{O}$ & $16 \mathrm{ml} / \mathrm{cmH}_{2} \mathrm{O}$ & $61 \mathrm{ml} / \mathrm{cm} \mathrm{H}_{2} \mathrm{O}$ & $33 \mathrm{ml} / \mathrm{cm} \mathrm{H}_{2} \mathrm{O}$ \\
\hline CI & No & No & Sí & No & No \\
\hline
\end{tabular}

Abreviaturas: CVM: Capacidad Vesical Máxima. PV a CVM: Presión Vesical a Capacidad Vesical Máxima. CI: Contracciones Involuntarias.

Tabla 4

Perforación de la cistoplastia.

\begin{tabular}{|c|c|c|c|c|c|}
\hline Caso & 1 & 2 & 3 & 4 & 5 \\
\hline Perforaciones & Una & Tres & Una & Una & Dos \\
\hline $\begin{array}{l}\text { Tiempor tras } \\
\text { Cistoplastia }\end{array}$ & $4 \mathrm{~A}+7 \mathrm{M}$ & $\begin{array}{c}1^{\mathrm{a}}: 3 \mathrm{~A}+9 \mathrm{M} \\
2^{\mathrm{a}}: 9 \mathrm{~A}+7 \mathrm{M} \\
3^{\mathrm{a}}: 11 \mathrm{~A}+3 \mathrm{M}\end{array}$ & $2 \mathrm{~A}+1 \mathrm{M}$ & $13 \mathrm{~A}+6 \mathrm{M}$ & $\begin{array}{c}1^{\underline{a}}: 6 \mathrm{~A}+8 \mathrm{M} \\
2^{\underline{a}}: 14 \mathrm{~A}+5 \mathrm{M}\end{array}$ \\
\hline $\begin{array}{l}\text { Edad a la } \\
\text { Perforación }\end{array}$ & 14 Años & $\begin{array}{c}1^{\mathrm{a}}: 6 \text { Años } \\
2^{\mathrm{a}}: 12 \text { Años } \\
3^{\mathrm{a}}: 14 \text { Años }\end{array}$ & 10 Años & 27 Años & $\begin{array}{l}1^{\mathrm{a}}: 15 \text { Años } \\
2^{\mathrm{a}}: 23 \text { Años }\end{array}$ \\
\hline $\begin{array}{l}\text { Control } \\
\text { Urológico }\end{array}$ & $\begin{array}{c}\text { Urologia de } \\
\text { Adultos }\end{array}$ & $\begin{array}{l}\text { Urología } \\
\text { Pediátrica }\end{array}$ & $\begin{array}{l}\text { Urología } \\
\text { Pediátrica }\end{array}$ & $\begin{array}{l}\text { Urología de } \\
\text { Adultos }\end{array}$ & $\begin{array}{l}\text { Urología de } \\
\text { Adultos }\end{array}$ \\
\hline
\end{tabular}

Abreviaturas A: Años. M: Meses.

$5(62,5 \%)$, disminución de la cantidad de orina obtenida con los sondajes en $3(37,5 \%)$ y cefalea en $1(12,5 \%)$.

El tiempo medio transcurrido entre la aparición de los primeros síntomas y el diagnóstico de perforación fue de 2,5 días (rango de 10 horas a 1 semana).

Las exploraciones de laboratorio realizadas fueron:

- Hemograma en 7 episodios, que mostró leucocitosis con neutrofilia en 6. Bioquímica sanguínea en 6 , con cifras elevadas de urea en 2 , creatinina en $1, \mathrm{y}$ ambas en otro paciente con insuficiencia renal crónica previa.
- Sedimento y cultivo de orina en 6 , con leucocituria en 3 , bacteriuria en 2 y cultivo positivo en 1.

- Bioquímica del líquido peritoneal realizada en 1 episodio, que mostró la presencia de urea.

Los estudios de imagen realizados fueron:

- Radiografía simple de abdomen en 4 episodios, que no mostró alteraciones en ninguno.

- Ecografía de abdomen en 7 episodios, con líquido libre intraperitoneal en 6 (Fig. 1), múltiples quistes peritoneales en $1, \mathrm{y}$ asas intestinales distendidas y fijas en fosa ilíaca derecha sugestiva de plastrón apendicular en el restante (este paciente se intervino con diagnóstico preoperato- 
Tabla 5

Diagnóstico de la perforación

\begin{tabular}{|c|c|c|c|c|c|}
\hline Caso & 1 & 2 & 3 & 4 & 5 \\
\hline $\begin{array}{l}\text { Tiempo } \\
\text { hasta el } \\
\text { diagóstico }\end{array}$ & 3 Días & $\begin{array}{c}1^{\underline{a}}: 2 \text { Dias } \\
2^{\underline{a}}: 10 \text { Horas } \\
3^{\text {a }}: 12 \text { Horas }\end{array}$ & 4 Días & 7 Días & $\begin{array}{l}1^{\text {a }}: 2 \text { Días } \\
2^{\underline{a}}: 1 \text { Día }\end{array}$ \\
\hline Clínica & $\mathrm{DD}, \mathrm{F}, \mathrm{NV}, \mathrm{DO}$ & $\begin{array}{c}1^{\mathrm{a}}: \mathrm{DD}, \mathrm{F}, \mathrm{NV} \\
2^{\mathrm{a}}: \mathrm{DD}, \mathrm{F} \\
3^{\mathrm{a}}: \mathrm{DD}\end{array}$ & DD,F,NV,DO & $\mathrm{DD}, \mathrm{F}, \mathrm{NV}, \mathrm{DO}, \mathrm{C}$ & $\begin{array}{c}1^{\mathrm{o}}: \mathrm{DD}, \mathrm{F}, \mathrm{NV} \\
2^{\mathrm{a}}: \mathrm{DD}\end{array}$ \\
\hline $\begin{array}{l}\text { Eco } \\
\text { Radiología }\end{array}$ & ECO: LLP & $\begin{array}{c}1^{\mathrm{a}}: \text { ECO: APDC } \\
2^{\underline{a}}: \text { ECO: LLP } \\
3^{\text {a }}: \text { CUMS,CTAC }\end{array}$ & $\begin{array}{l}\text { ECO: Quistes } \\
\text { peritoneales } \\
\text { múltiples }\end{array}$ & $\begin{array}{l}\text { ECO: LLP } \\
\text { CUMS }\end{array}$ & $\begin{aligned} 1^{\mathrm{a}}: \text { ECO: LLP } \\
2^{\mathrm{a}}: \text { ECO:LLP, } \\
\text { CTAC }\end{aligned}$ \\
\hline $\begin{array}{l}\text { Tipo de } \\
\text { perforación }\end{array}$ & Líquido libre & Liquido libre & Quística & Líquido libre & Líquido libre \\
\hline $\begin{array}{l}\text { Lugar } \\
\text { de la } \\
\text { perforación }\end{array}$ & Intestino & $\begin{array}{c}1^{\mathrm{a}}: \text { Intestino } \\
2^{\mathrm{a}}: \text { Desconocido } \\
3^{\mathrm{a}}: \text { Intestino }\end{array}$ & Desconocido & Desconocido & $\begin{array}{c}1^{\mathrm{a}}: \text { Desconocido } \\
2^{\mathrm{o}}: \text { Intestino }\end{array}$ \\
\hline
\end{tabular}

Tabla 6

Tratamiento de la perforación y evolución posterior

\begin{tabular}{|c|c|c|c|c|c|}
\hline Caso & 1 & 2 & 3 & 4 & 5 \\
\hline Tratamiento & $\begin{array}{c}1^{\circ}: \mathrm{Qx} \\
\mathrm{Co}+\mathrm{Qx}\end{array}$ & $\begin{array}{c}1^{\mathrm{o}}: \text { Co } \\
2^{\circ}: \text { Co } \\
3^{\mathrm{o}}: \text { Co }+\mathrm{Qx}\end{array}$ & $\mathrm{Co}+\mathrm{Qx}$ & Co & $2^{\mathrm{o}}: \mathrm{Co}+\mathrm{Qx}$ \\
\hline Evolución & Favorable & $\begin{array}{l}1^{\mathrm{a}}: \text { Favorable } \\
2^{\underline{a}}: \text { Favorable } \\
3^{\underline{a}}: \text { Favorable }\end{array}$ & Favorable & Favorable & $\begin{array}{l}1^{\mathrm{a}}: \text { Favorable } \\
2^{\mathrm{a}}: \text { Favorable }\end{array}$ \\
\hline Recidivas & Ninguna & Dos & Ninguna & Ninguna & Una \\
\hline Seguimiento & $7 A+9 M$ & $6 \mathrm{M}$ & $4 \mathrm{~A}+7 \mathrm{M}$ & $7 \mathrm{M}$ & $7 \mathrm{M}$ \\
\hline
\end{tabular}

Abreviaturas: Co: Tratamiento Conservador. Qx: Tratamiento Quirúrgico.

rio de apendicitis, diagnosticándose intraoperatoriamente la perforación de la cistoplastia y la peritonitis secundaria).

- Cistografía en 5: En 3 fue un Cistograma convencional (CUMS), mostrando la extravasación de contraste desde la vejiga hacia la cavidad peritoneal en 2 (Fig. 2). En los otros 2 fue una Cistografía con tomografía axial computerizada (Cisto-TAC), poniendo de manifiesto la perforación de la cistoplastia con paso de contraste a la cavidad peritoneal en 1 (Figs. 3, 4 y 5); en el caso restante, aunque no objetivó una imagen de fuga del contraste, sí mostró una vejiga distendida con una pared muy engrosada, con una zona adelgazada en la porción intestinal de la cistoplastia, y abundante líquido libre intraperitoneal. En total sólo se demostró el paso de contraste de vejiga a peritoneo en 3 de los 5 casos en que se realizó cistografía (60\%).

El diagnóstico de sospecha de perforación se realizó, en 7 de los 8 episodios, por los antecedentes del paciente, la clínica y las exploraciones analíticas y radiológicas. El episodio restante se diagnosticó durante una intervención con diagnóstico de sospecha de plastrón apendicular.

La localización de la perforación, mediante los estudios radiológicos o bien durante la cirugía, fue posible en 4 de los 8 episodios (50\%), y siempre fue en la parte intestinal de la cistoplastia (íleon en 3 casos y sigma en 1). En los 4 restantes no se pudo localizar, debido a la imposibilidad para visualizarla durante la cirugía en 1 caso, y a la no realización de tratamiento quirúrgico en los otros 3. 


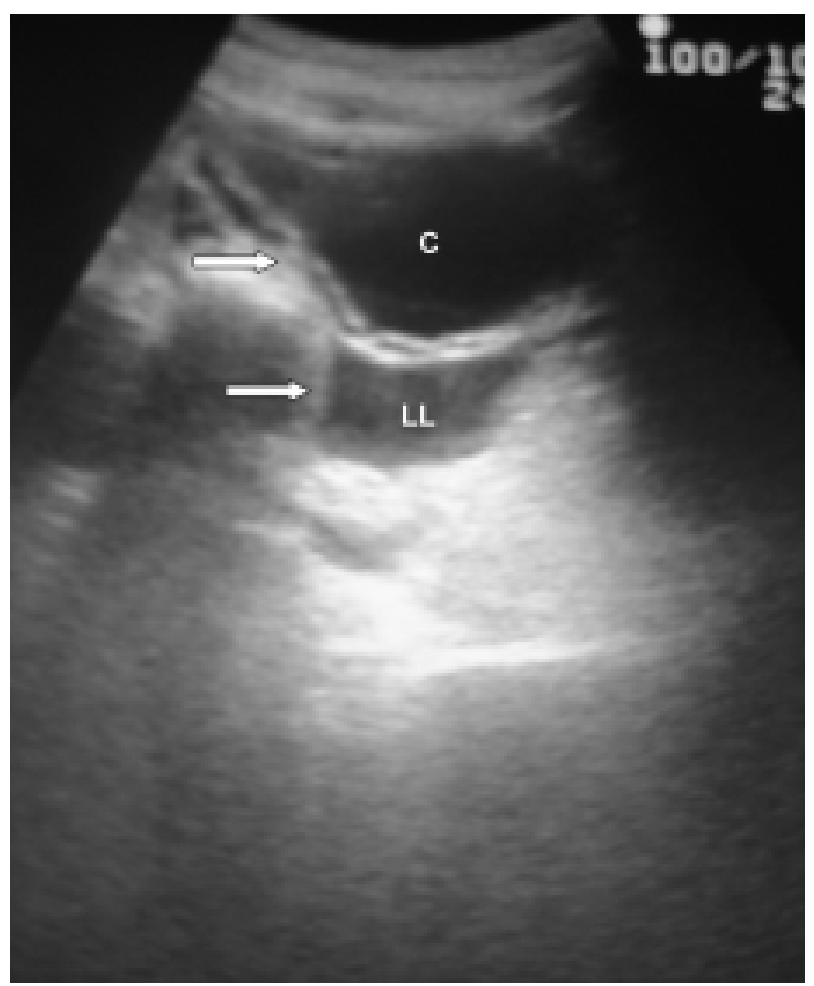

FIGURA 1. Ecografia pélvica: Cistoplastia (C) a media repleción con abundante liquido libre (LL) en Douglas y peritoneo.

La orina intraperitoneal produjo ascitis urinaria en 7 episodios, y un gran quiste multiloculado de unos $600 \mathrm{ml}$ en el restante.

El tratamiento fue inicialmente conservador en los 7 episodios con diagnóstico de sospecha de perforación. Consistió en sueroterapia con reposición hidroelectrolítica, antibióticos intravenosos, y sonda vesical permanente. Tres episodios evolucionaron favorablemente, sin precisar tratamiento quirúrgico. En los otros 4 episodios fue necesaria, además, la cirugía: laparotomía, aspiración y lavado de la cavidad peritoneal, cierre de la perforación en dos planos, y drenaje paravesical. En todos la evolución posterior fue favorable $\mathrm{y}$ sin complicaciones.

Sólo en el episodio de perforación en el que el diagnóstico inicial fue de apendicitis, el tratamiento fue quirúrgico de entrada, evolucionando también de forma favorable y sin complicaciones.

El resultado ha sido bueno, sin complicaciones y con evolución favorable en todos los episodios.

Recidivas: Dos de los cinco pacientes presentaron nueva perforación tras el primer episodio (40\%): Un paciente tuvo dos perforacio-

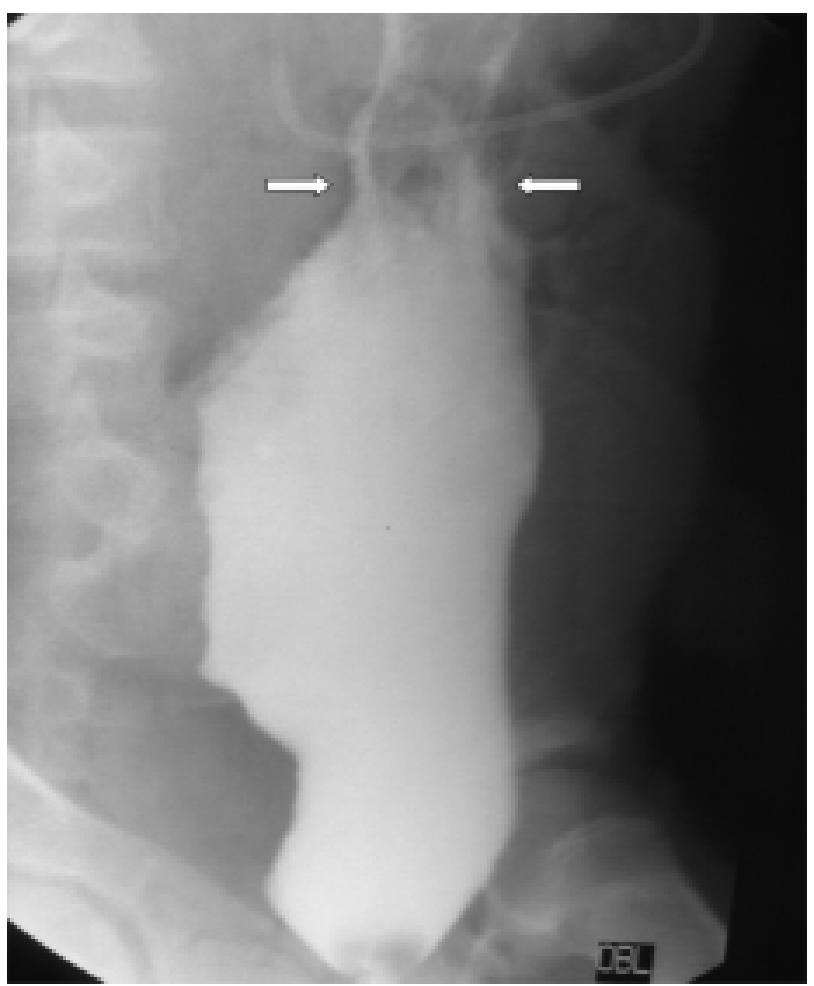

FIGURA 2. CUMS: Proyección oblicua que muestra una perforación amplia en la cúpula de la cistoplastia con extravasación de contraste. Catéter de derivación ventriculoperitoneal.

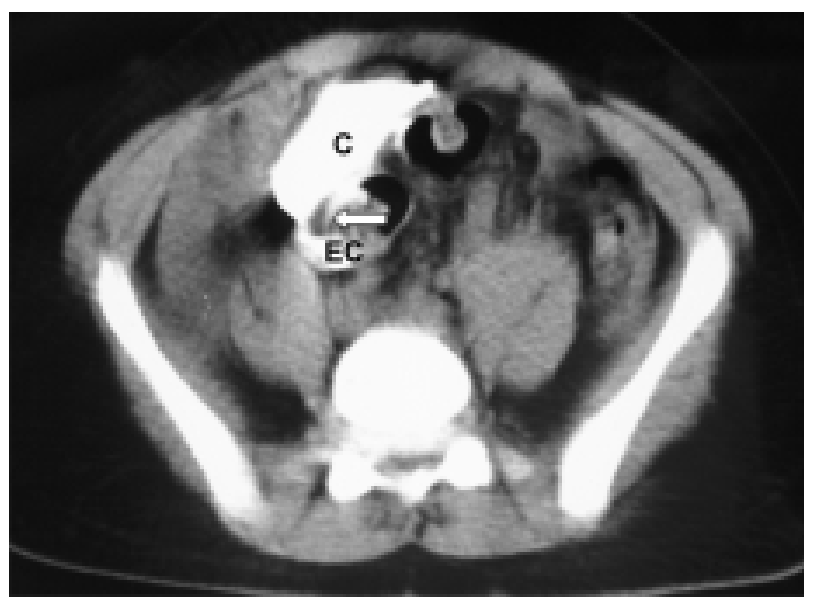

FIGURA 3. Cisto-TAC: Perforación de la cúpula de la cistoplastia (C) con extravasación de contraste (EC).

nes, y otro una. El tiempo medio de producción de las recidivas fue de 5 años (rango de 1,7 a 7,7 años).

El seguimiento de estos cinco pacientes, desde su último episodio de perforación, ha sido de 2,8 años (rango de 5 meses a 7,7 años). Actualmente todos tienen la cistoplastia funcionante, sin complicaciones. 


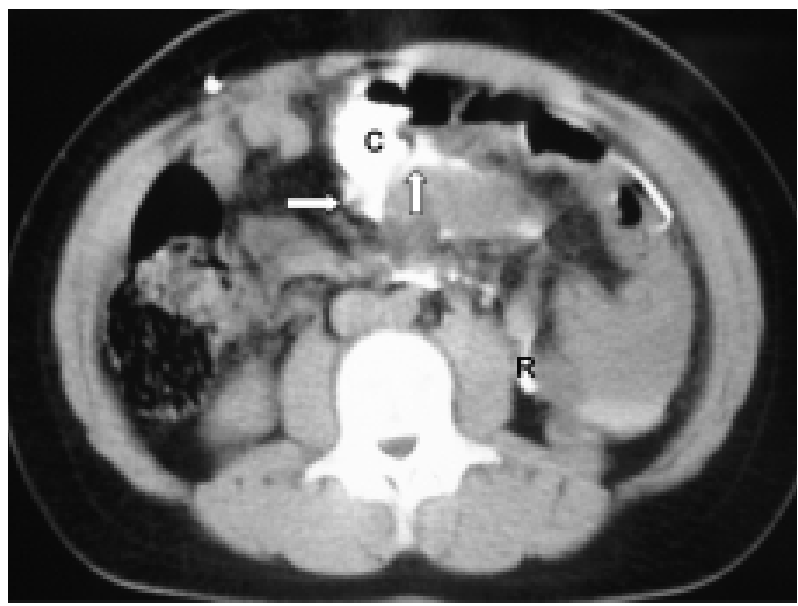

FIGURA 4. Cisto-TAC: Extravasación de contraste desde la cistoplastia (C) hacia la cavidad peritoneal. Reflujo (R) en uréter izquierdo.

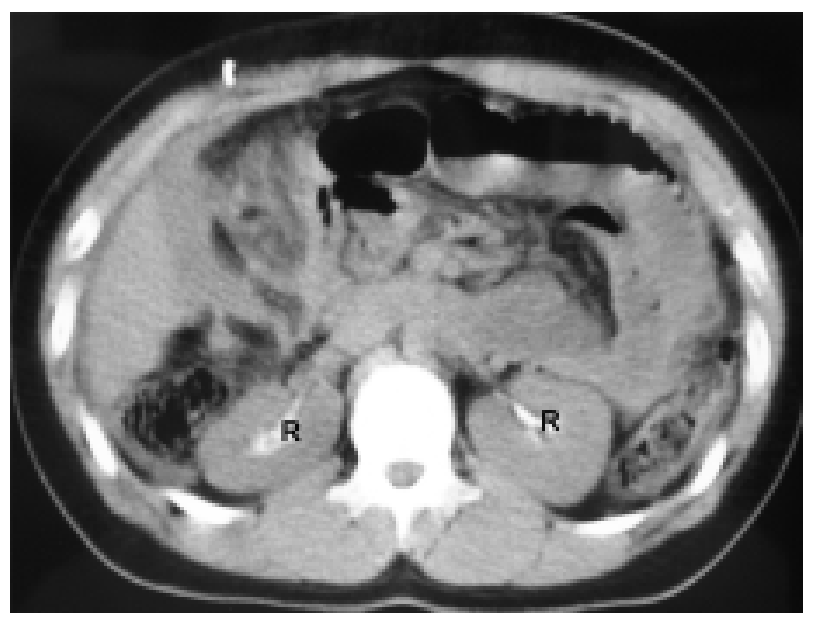

FIGURA 5. Cisto-TAC: Reflujo (R) en ambos sistemas pielocaliciales.

\section{DISCUSIÓN}

La perforación vesical espontánea es una complicación potencialmente fatal que ocurre en niños con patología vesical, generalmente neuropática, que se ha tratado con una cistoplastia y desde entonces se maneja con sondaje intermitente (SI). La perforación espontánea también se presenta, aunque con menor frecuencia, en vejigas ampliadas no neuropáticas, como en la extrofia vesical o en las válvulas de uretra posterior ${ }^{1}$. Sin embargo, es excepcional en niños que no tienen el antecedente de cirugía vesical, habiéndose descrito algún caso esporádico en fetos y neonatos con obstrucción al tracto de salida vesical, generalmente secundario a válvulas de uretra posterior $^{2}$, o en niños más mayores, secundaria- mente a un traumatismo abdominal sobre una vejiga distendida ${ }^{3,4}$. En esta serie, cuatro de los cinco pacientes tenían una vejiga neuropática (80\%), y el otro unas válvulas de uretra posterior. Shekarriz recoge una distribución similar, con un $88 \%$ de vejigas neuropáticas ${ }^{5}$.

En los cinco pacientes se había realizado una enterocistoplastia, asociando en dos de ellos la colocación de un esfínter artificial. La edad media en el momento de la cirugía fue 8,2 años (rango de 2 a 13 años).

La enterocistoplastia se había realizado con íleon en 3 casos y sigma en 2 . Teniendo en cuenta que de las 30 cistoplastias de esta serie, 7 se realizaron con íleon y 20 con sigma, el índice de perforación fue mayor en las ileocistoplastias $(42,8 \%)$ que en las sigmoidocistoplastias (10\%).

La incidencia de perforación según el segmento gastrointestinal utilizado es muy diversa según los diferentes autores: En algunas series, el 100\% de las perforaciones ocurre en ileocistoplastias ${ }^{3}$, en otras en sigma ${ }^{6,7}$, mientras que otros autores no encuentran diferencias estadísticamente significativas entre un segmento y otro ${ }^{5,8}$.

La cirugía de la continencia asociada a la cistoplastia, tanto la realizada a nivel del cuello vesical, como la creación de estomas vesicales continentes, no parece influir en el riesgo de perforación ${ }^{3,5,6}$.

La prevalencia de perforación de las cistoplastias oscila entre el 3 y el $13 \% \%^{3,5,8-11}$, siendo en esta serie del $16,6 \%$.

El tiempo medio transcurrido entre la realización de la cistoplastia y la presentación de la perforación, oscila entre 1,8 y 3,8 años ${ }^{3,5,6,9}$, sin embargo en esta serie, fue de 8,2 años. Quizás la mayor prevalencia de perforaciones de esta serie pediátrica se deba a un mayor seguimiento a largo plazo, durante la adolescencia.

Las perforaciones ocurridas durante el primer año postoperatorio, suelen producirse a nivel de la anastomosis vesico-intestinal, mientras que las que ocurren con posterioridad, suelen asentar a nivel intestinal ${ }^{1,12}$. En esta serie, todas las perforaciones se produjeron de forma tardía y asentaron a nivel del asa intestinal de la cistoplastia.

Los factores de riesgo de perforación, generalmente interrelacionados, pueden agruparse en tres grupos: 
1) Aumento de presiones vesicales - sobredistensión - isquemia: Una elevación de las presiones vesicales, generalmente secundario a sobredistensión vesical (por poliuria, vaciado vesical incompleto o sondaje insuficiente), puede conducir a una isquemia de la pared, que favorezca la perforación ${ }^{1,3,13}$. Experimentalmente se ha demostrado que elevaciones de las presiones intravesicales por encima de los $33 \mathrm{~cm} \mathrm{H}_{2} \mathrm{O}$, reducen el flujo sanguíneo en los segmentos de colon, pudiendo favorecer la perforación vesi$\mathrm{cal}^{14}$. En una serie de 5 episodios de perforación en reservorios vesicales realizados con íleon destubulizado, todos tenían el antecedente de una sobredistensión del reservorio, que fue crónica en 3 episodios y aguda en los otros 2 . La biopsia de pared obtenida durante la cirugía, presentó isquemia crónica en los 3 casos que presentaron sobredistensión crónica ${ }^{10}$. La destubulización del intestino aumenta el radio del segmento, con lo cual, según la ley de Laplace, aumenta la tensión de la pared, lo que produce una reducción del flujo sanguíneo e isquemia de la mucosa y la muscular ${ }^{10}$. En esta serie todos los casos de perforación se desencadenaron en vejigas con una situación previa de sobredistensión.

2) Continencia - sondaje intermitente - moco vesical - infecciones: Una continencia satisfactoria puede ser un factor de riesgo de perforación: Según una revisión bibliográfica, la mayoría de los casos de perforación eran continentes con ayuda del sondaje $\mathrm{e}^{3,6,15}$. En esta serie, la continencia previa era total, diurna y nocturna, en 4 pacientes y sólo diurna en el caso restante. Además, 3 de los 5 pacientes tenían un esfínter urinario artificial funcionante en el momento de la perforación.

Es fundamental realizar adecuadamente el sondaje intermitente adecuando la frecuencia a la diuresis habitual del paciente tras la ampliación vesical. En nuestra experiencia, el principal factor predisponente fue un sondaje inadecuado, con una frecuencia insuficiente para la diuresis, fundamentalmente en dos pacientes que tenían poliuria. Por otro lado, el SI supone un microtraumatismo repetido sobre la pared de la cistoplastia sobredistendida que, con el tiempo, puede debilitarla y favorecer una perforación ${ }^{3,6}$. En una serie de 17 perforaciones en pacientes pediátricos, se observó que el retraso en la realización de los sondajes, con la sobredistensión vesical resultante, contribuyó a la perforación en 5 pacientes, mientras que el sondaje traumático resultó ser la causa de la perforación en otro ${ }^{5}$. Se ha comprobado que el número óptimo es de 5 a 6 sondajes diarios, pues conlleva un menor riesgo de perforación ${ }^{3}$.

El moco vesical puede dificultar el sondaje y favorecer la perforación ${ }^{5}$.

La infección transmural puede propiciar el desarrollo local de isquemia, lo que a su vez puede evolucionar a la perforación de la cistoplastia $^{3}$, habiéndose descrito casos de perforación en pacientes con episodios previos de cistitis por pseudomona ${ }^{5}$.

3) Aspectos relacionados con la cirugía de la cistoplastia: La configuración del segmento gastro-intestinal utilizado, puede influir en el riesgo de perforación al favorecer la aparición de focos de isquemia y necrosis en los que, posteriormente, sea más posible la perforación ${ }^{3}$. Según algunos autores, la mayoría de las perforaciones a nivel de la anastomosis vesico-intestinal, tienen lugar en intestino no destubulizado, mientras que las perforaciones del asa de intestino corresponden a intestino destubulizado ${ }^{12}$. La mayoría de los autores opina que la destubulización, a pesar del riesgo potencial de crear áreas de isquemia, es recomendable, pues reduce el peristaltismo intestinal y aumenta la capacidad vesical ${ }^{12}$. En los 4 pacientes de esta serie en los que se localizó la perforación, siempre fue en el asa intestinal. Algunos autores consideran que usando estómago se reduce el riesgo de perforación pues se evita la necesidad de configurarlo y por tanto la sutura intestino-intestinal ${ }^{16}$.

En pacientes con apendico-vesicostomía, la ruptura suele producirse en la anastomosis apendico-vesical $^{17}$.

Otro factor es el tipo de sutura de la cistoplastia: Se ha visto que la sutura en dos planos hace más difícil el desarrollo de perforaciones a nivel de la zona anastomótica ${ }^{3,12,18}$. En los cinco pacientes de esta serie, la sutura de la cistoplastia se había realizado en dos planos.

Durante el postoperatorio se crean bridas $y$ adherencias alrededor de la cistoplastia que le confieren una morfología fija, con menor flexibilidad. Esto puede predisponer a la perforación ${ }^{6,10}$. 
El antecedente de una perforación espontánea previa supone un factor de riesgo añadido ${ }^{6,19}$. En esta serie existía el antecedente de perforación previa en 3 de los 8 episodios y en 2 de los 5 pacientes.

Un retraso en el diagnóstico de la perforación puede resultar fatal. Por eso es fundamental realizar un diagnóstico precoz, lo que requiere un alto índice de sospecha ${ }^{15}$ :

1) Sintomas: El dolor y la distensión abdominal son prácticamente constantes en el $100 \%$ de los $\operatorname{casos}^{11}$, como ocurre en nuestra serie. Otros síntomas son fiebre, náuseas, vómitos, oliguria, hipotensión, taquicardia y sudoración ${ }^{1}$. Sin embargo, los pacientes con mielodisplasia, debido a la menor sensibilidad visceral que tienen, pueden desarrollar abscesos intraperitoneales o incluso peritonitis antes de que la perforación sea evidente clínicamente ${ }^{9}$. También se han descrito shock séptico ${ }^{3,5}$, distress respiratorio ${ }^{5}$ o dolor en hombro derecho ${ }^{15}$.

2) Analitica: En el hemograma es frecuente la leucocitosis con neutrofilia ${ }^{5,6}$. La reabsorción de orina por el peritoneo produce un aumento de urea y creatinina en la bioquímica sanguinea ${ }^{9}$ pudiendo confundir el diagnóstico con un fallo renal agudo o una uropatía obstructiva ${ }^{1}$. En los pacientes que realizan SI es habitual una bacteriuria crónica, por lo que el urocultivo y el sedimento urinario suelen ser patológicos, y no contribuyen al diagnóstico de perforación ${ }^{6,9}$, (sin embargo pueden inducir a un diagnóstico erróneo inicial de infección urinaria, que retrasa el diagnóstico de perforación, con fatales consecuencias ${ }^{15}$ ). Los pacientes con cistoplastia suelen tener la orina colonizada con bacterias y la perforación vesical puede producir una peritonitis química y bacteriana ${ }^{1,10}$, con un cultivo del líquido peritoneal positivo y tasas de mortalidad de hasta el $25 \%{ }^{9}$.

3) Estudios de imagen: En la radiografia de abdomen en vacio, puede verse una imagen de íleo paralítico secundario a la perforación ${ }^{9}$ o de obstrucción intestinal $^{6}$. En esta serie, la radiografía no mostró alteraciones en ninguno de los 4 casos en que se realizó. La ecografía aporta signos indirectos de perforación, pudiendo identificar abscesos, urinomas o líquido libre. Hay que hacer el diagnóstico diferencial con quistes de líquido cefalorraquídeo (LCR) secundarios al catéter ventrículo peritoneal (CVP) ${ }^{6,9,15}$. En otros casos, urinomas paraureterales pueden producir hidronefrosis por compresión ${ }^{1}$. Algunos autores preconizan la utilidad del "cistograma champán”, consistente en la irrigación rápida de la cistoplastia con suero fisiológico, lo que crea pequeñas burbujas de aire fácilmente visibles con ecografía, que son fácilmente identificables $^{6}$. En ocasiones, el estudio ecográfico puede evidenciar un plastrón intestinal, como ocurrió en un caso de esta serie. El CUMS puede localizar la ruptura en algunos $\operatorname{casos}^{5,6,11,15}$. Sin embargo, aunque resulta de gran utilidad para diagnosticar perforaciones en vejigas normales, presenta una tasa de hasta un $75 \%$ de falsos negativos cuando se utiliza para diagnosticar perforaciones de vejigas ampliadas, debido a que la perforación tiende a autoprotegerse con coágulos, tapones de moco, fibrina, asas intestinales o epiplon ${ }^{20}$. Es conveniente llenar por completo la cistoplastia y obtener imágenes oblicuas. Se deben obtener imágenes tras el vaciado para visualizar mejor el material de contraste extravasado ${ }^{21}$, aunque dada la morfología abigarrada de las cistoplastias, puede resultar difícil identificar pequeñas fugas y localizar el punto exacto de la misma ${ }^{6}$. En esta serie se realizó CUMS en 3 casos demostrando paso de contraste a peritoneo en 2. En los casos en que el CUMS ha sido negativo, es de gran utilidad realizar un Cisto-TAC pues tiene mayor sensibilidad para detectar extravasaciones de escaso volumen o colecciones muy localizadas ${ }^{1}$ con menor dosis de radiación que el CUMS convencional ${ }^{15}$. Sin embargo un resultado negativo no debe excluir el diagnóstico de perforación si la sospecha clínica es alta, pues se han descrito casos de retraso diagnóstico por este motivo ${ }^{3}$. En esta serie se realizó Cisto-TAC en 2 casos, en los que fue de gran ayuda para el diagnóstico. El TAC abdominal y pélvico con contraste, permite detectar líquido libre intraperitoneal, abscesos e inflamación de la pared vesical ${ }^{9}$, constituyendo el mejor método diagnóstico para demostrar abscesos o urinomas adyacentes a la vejiga ${ }^{6}$. Algunos autores han realizado cistoscopia en casos de perforación, visualizando un área de necrosis en la pared de la cistoplastia ${ }^{15}$. 
En un gran porcentaje de casos, el diagnóstico de sospecha se hace por los antecedentes, la clínica y la exploración física (Tabla 7), mientras que el diagnóstico de confirmación se obtiene con la ecografía y el CUMS o el Cisto-TAC. Sin embargo, también es frecuente hacer un diagnóstico intraoperatorio $^{9}$ tras un diagnóstico inicial de oclusión intestinal por bridas ${ }^{5,6,8,11} \mathrm{u}$ otras causas de abdomen agudo ${ }^{1,6,22}$.

\section{Tabla 7}

Datos para el diagnóstico de sospecha de perforación de una cistoplastia

\section{Patología de base}

- Disfunción vesico esfinteriana, tratada con enterocistoplastia

- Mielodisplasia

\section{Antecedentes}

- Sondajes infrecuentes y/o poliuria

- Continencia entre sondajes

- Perforación previa

\section{Clínica}

- Dolor y/o distensión abdominal

- Náuseas y/o vómitos

- Disminución de la diuresis obtenida con los sondajes vesicales

\section{Laboratorio}

- Leucocitosis, neutrofilia

- Aumento de urea y/o creatinina en sangre

\section{Eco Radiología}

- Distensión intestinal y / o líquido libre entre asas (radiografía)

- Colecciones paravesicales o líquido libre abdominal (ecografía)

- Contraste intraperitoneal (cistograma)

Se ha descrito algún caso tratado erróneamente de infección urinaria, falleciendo al poco tiempo por una perforación vesical no diagnosticada ${ }^{11}$.

El diagnóstico suele ser más difícil en los pacientes mielodisplásicos, por varios motivos: 1) Anormal percepción del dolor abdominal; 2) Cifoescoliosis que dificulta el estudio radiológico, y 3) Diversas posibilidades etiológicas de abdomen agudo (perforación y obstrucción intestinal, complicaciones derivadas del CVP, intestino neurógeno, etcétera) ${ }^{7}$.

La perforación puede ser intraperitoneal, extraperitoneal o ambas ${ }^{1}$, y estar localizada (urinoma) o diseminada (ascitis urinosa), pudiendo además estar infectada originando un absceso o una peritonitis.
Cuando la sospecha de perforación es alta, el tratamiento debe ser precoz mientras se realizan el resto de las exploraciones, porque el riesgo de sepsis fatal aumenta con el retraso en el diagnóstico y por lo tanto del tratamiento. Si el estado del paciente lo permite, puede iniciare un tratamiento conservador consistente en reposición hidroelectrolítica, antibióticos de amplio espectro sensibles a los gérmenes habituales y drenaje vesical permanente con una sonda de Foley, con controles analíticos y ecográficos periódicos ${ }^{6}$. Si con este tratamiento no mejora, debe realizarse un tratamiento quirúrgico consistente en laparotomía exploradora, desbridamiento de urinomas o abscesos, drenaje del líquido extravasado, cierre de la perforación vesical, y colocación de un drenaje suprapúbico a través de la pared vesical ${ }^{6}$. Algunos autores piensan que el tratamiento conservador puede ser suficiente en los casos en que no hay signos de irritación peritoneal. En una serie de 15 perforaciones, 12 respondieron al tratamiento con drenaje vesical y antibióticos $(80 \%)^{23}$. Sin embargo otros autores son partidarios del tratamiento quirúrgico. En otra serie de 17 perforaciones el tratamiento conservador fue suficiente únicamente en 1 caso $(6 \%)^{5}$. En esta serie, 3 de los 7 episodios tratados inicialmente de forma conservadora respondieron bien (43\%), no siendo necesaria la cirugía.

En los abscesos crónicos, se requiere un drenaje abierto, que en pacientes extremadamente graves y sépticos, puede ser percutáneo, guiado por ecografía o TAC $^{6,11,23}$.

La laparotomía exploradora permite confirmar la perforación y es resolutiva en muchos casos, pero puede resultar complicada en casos de múltiples cirugías abdominales previas. Para algunos autores, entre los que nos incluimos, las indicaciones de cirugía son: 1) Evidencia de peritonitis o sepsis; 2) Persistencia de los síntomas más de 48 horas; 3) Descompensación hemodinámica; 4) Deterioro clínico en 48 horas $^{23}$.

Se han descrito algunas complicaciones tras la cirugía como abscesos intraabdominales y fístulas vesicocutáneas ${ }^{5}$.

En cuanto a la evolución, los 4 casos de esta serie que precisaron cirugia a pesar del tratamiento conservador, evolucionaron favorablemente. $\mathrm{El}$ caso restante, tratado quirúrgicamente de entrada por diagnóstico inicial de plastrón apendicular, también evolucionó sin complicaciones. 
En algunos casos la perforación puede tener una evolución fatal, generalmente debido a un retraso en el diagnóstico y en el tratamiento de la perforación. En una revisión bibliográfica se describen 3 casos de fallecimiento, 2 tras el cierre quirúrgico $6,11,15$.

Otro aspecto importante es la recidiva de la perforación: En revisiones amplias de la bibliografía, diversos autores estiman el índice de recurrencia en aproximadamente un 33-36\% de los pacientes, ocurriendo ésta entre 2 meses y 6 años tras la primera perforación ${ }^{3,6,12,20,23}$. En esta serie, dos de los cinco pacientes con perforación de la cistoplastia (40\%) presentaron 3 recidivas, que se produjeron entre 1,7 y 7,7 años después del episodio anterior, con un tiempo medio de 5 años. Esta mayor prevalencia de recidivas creemos que guarda relación con un seguimiento más prolongado, incluso en la vida adulta.

\section{CONCLUSIONES}

La perforación vesical espontánea tras la cistoplastia es una complicación grave y frecuente, que requiere una completa información de sus riesgos a los pacientes con cistoplastia y a sus familiares, para establecer una adecuada profilaxis.

Es necesario un diagnóstico precoz, basado principalmente en la sospecha clínica por el dolor y la distensión abdominal, sobre todo si se acompañan de una disminución de la diuresis.

Los factores de riesgo más significativos son una resistencia uretral alta que permita la continencia, y una realización inadecuada del SI, asociados a una distensión crónica de la cistoplastia.

El tratamiento debe ser precoz: Inicialmente, si no hay peritonitis, sepsis o gran desequilibrio hidroelectrolítico, puede ser conservador, seguido de cirugía si no hay mejoría en las primeras 24-48 horas.

Un retraso en el diagnóstico y el tratamiento aumenta el riesgo de evolución fatal.

\section{REFERENCIAS}

1. Zerin JM. Uroradiologic emergencies in infants and children. Radiol Clin North Am 1997;35(4):897-919.

2. Trulock TS, Finnert DP, Woodard JR. Neonatal bladder rupture: Case report and review of literature. J Urol 1985;133:271-273.

3. De Foor W, Tackett L, Minevich E, Wacksman J, Sheldon C. Risk factors for spontaneous bladder perforation alter augmentation cystoplasty. Urology 2003;62(4):737-741.

4. Sivit CJ, Cutting JP, Eichelberger MR. CT diagnosis and localization of rupture of the bladder in children with blunt abdominal trauma: Significance of contrast material extravasation in the pelvis. Am J Roentgenol 1995;164: 1243-1246.
5. Shekarriz B, Upadhyay J, Demirbilek S, Barthold SJ, Gonzalez R. Surgical complications of bladder augmentation: Comparison between various enterocystoplasties in 133 patients. Urology 2000; 55(1): 123-128.

6. Elder J, Snyder H, Hulbert W, Duckett J. Perforation of the augmented bladder in patients undergoing clean intermittent catheterization. J Urol 1988; 140:1159-1162.

7. Worley G, Wiener JS, George TM, Fuchs HE, Mackey JF, Fitch RD. Acute abdominal symptoms and signs in children and young adults with spina bifida: Ten years' experience. J Pediatr Surg 2001;36(9): 1381-1386.

8. Bertschy C, Bawab F, Liard A, Valioulis I, Mitrofanoff P. Enterocystoplasty complications in children. A study of 30 cases. Eur J Pediatr Surg 2000;10:30-34.

9. Rogers CJ, Barber DB, Wade WH. Spontaneous bladder perforation in paraplegia as a late complication of augmentation enterocystoplasty: Case report. Arch Phys Med Rehabil 1996;77:1198-1200.

10. Desgrandchamps F, Cariou G, Barthelemy Y, Boyer C, Teillac P, Le Duc A. Spontaneous rupture of orthotopic detubularized ileal bladder replacement: Report of 5 cases. J Urol 1997;158(3):798-800.

11. Fontaine E, Leaver R, Woodhouse CR. Diagnosis of perforated enterocystoplasty. J R Soc Med 2003;96(8):393-396.

12. Bauer SB, Hendren WH, Kozakewich H. Perforation of the augmented bladder. J Urol 1992;148:699-703.

13. Crane JM, Scherz HS, Billman GF, Kaplan G W. Ischemic necrosis: A hypothesis to explain the pathogenesis of spontaneously ruptured enterocystoplasty. J Urol 1991;146: 141-144.

14. Essig KA, Sheldon CA, Brandt MT, Wacksman J, Silverman DG. Elevated intravesical pressure causes arterial hypoperfusion in canine colocystoplasty: A fluorometric assessment. J Urol 1991; 146:551-553.

15. Couillard DR, Vapnek JM, Rentzepis MJ, Stone AR. Fatal perforation of augmentation cystoplasty in an adult. Urology 1993;42:585588.

16. Atala A, Bauer SB, Hendren WH. The effect of gastric augmentation on bladder function. J Urol 1993;149:1099-1102.

17. Cendron M, Gearhart JP. The Mitrofanoff principle: Technique and application in continent urinary diversion. Urol Clin North Am 1991;18:615-621.

18. Hendren WH, Hendren RB. Bladder augmentation: Experience with 129 children and young adults. J Urol 1990;144:445-460.

19. Pope JC, Albers P, Rink RC. Spontaneous rupture of the augmented bladder: From silence to chaos: Proceedings of the Annual Meeting of the European Society of Pediatric Urology, Instanbul. Turkey, April 1999.

20. Rosen MA, Light JK. Spontaneous bladder rupture following augmentation enterocystoplasty. J Urol 1991;146: 1232-1234.

21. Gheorghiu V, Costache C, Radu V, Taranu T. The contribution of cystography in the diagnosis of bladder trauma. Rev Med Chir Soc Med Nat Lasi 2003;107(3):603-608.

22. Kiliç N, Celayir S, Eliçevik M, Sarimurat N, Soylet Y. Bladder augmentation: Urodynamic findings and clinical outcome in different augmentation techniques. Eur J Pediatr Surg 1999;9:29-32.

23. Slaton JW, Kroppk A. Conservative management of suspected bladder rupture after augmentation enterocystoplasty. J Urol 1994; 152:713-715.

Dr. C. Miguélez Lago

Figurillas 4. El Olivar.

29620 Torremolinos (Málaga)

e-mail: miguelezlago@hotmail.com

(Trabajo recibido el 13 junio de 2005) 